\title{
Novel Murine Norovirus-Like Genes in Wild Rodents in Japan
}

\author{
Naoto TSUNESUMI ${ }^{1)}$, Go SATO ${ }^{1)}$, Masahiro IWASA ${ }^{2)}$, Hidenori KABEYA ${ }^{3)}$, Soichi MARUYAMA ${ }^{3)}$ and \\ Yukinobu TOHYA ${ }^{1)}$ \\ ${ }^{1)}$ Laboratory of Veterinary Microbiology, Department of Veterinary Medicine, College of Bioresource Sciences, Nihon University, 1866 \\ Kameino, Fujisawa, Kanagawa 252-0880, Japan \\ 2) Laboratory of Wildlife Science, Department of Animal Science and Resources, College of Bioresource Sciences, Nihon University, \\ 1866 Kameino, Fujisawa, Kanagawa 252-0880, Japan \\ ${ }^{3)}$ Laboratory of Veterinary Public Health, Department of Veterinary Medicine, College of Bioresource Sciences, Nihon University, 1866 \\ Kameino, Fujisawa, Kanagawa 252-0880, Japan
}

(Received 7 March 2012/Accepted 21 April 2012/Published online in J-STAGE 16 May 2012)

ABSTRACT. Novel murine norovirus (MNV)-like sequences were detected in 7 (14.9\%) of 47 fecal and intestinal samples obtained from wild rodents in Japan. Sequencing and genetic analyses of the 7 MNV-like genes, 6 derived from Apodemus speciosus and 1 from Rattus rattus, suggested that these sequences form a cluster distinct from known MNV within genogroup V and differed even among clusters of wild rodents. Considering these results, MNV might be genetically diverse depending on the host species or distribution. This is the first report suggesting the prevalence of MNV in $A$. speciosus and $R$. rattus.

KEY WORDS: Apodemus speciosus, Caliciviridae, murine norovirus, Rattus rattus, wild rodent.

doi: 10.1292/jvms.12-0106; J. Vet. Med. Sci. 74(9): 1221-1224, 2012

Noroviruses comprise five genogroups (GI to GV) of single-stranded, positive-sense RNA viruses that belong to the genus Norovirus in the family Caliciviridae [11, 16]. The GI and GII viruses are responsible for majority cases of acute non-bacterial gastroenteritis worldwide among humans of all ages $[3,10]$. Despite their importance to public health, the absence of cell culture [2, 8] and small animal model [4] systems have rendered the studying of noroviruses difficult. However, murine norovirus (MNV), which was discovered in the U.S.A. and classified as GV [6], can propagate in the RAW 264.7 cell line that is derived from mouse macrophages [1, 14]. Therefore, MNV has been investigated as a human norovirus surrogate [15]. MNV infection is widespread in laboratory mice, and multiple MNV strains have been detected in laboratory mice across the world [5]. Furthermore, a recent study demonstrated that MNV is present not only in wild-mice (Mus musculus) but also in wood mice (Apodemus sylvatics) in UK [12]. However, no evidence for the existence of MNV in wild rodents in Asia including Japan has been found. This study therefore aimed to detect and characterize MNV in wild rodents.

We collected 47 fecal or intestinal samples from wild rodents (44 Apodemus speciosus, 1 Rattus rattus, 1 Apodemus argenteus and 1 Microtus montebelli) between May 2009 and January 2011 in Chiba, Kanagawa and Niigata prefectures, Japan. Solutions of PBS containing 10\% fecal

\footnotetext{
*CORRESPONDENCE TO: TOHYA,Y., Laboratory of Veterinary Microbiology, Department of Veterinary Medicine, College of Bioresource Sciences, Nihon University, 1866 Kameino, Fujisawa, Kanagawa 252-0880, Japan.

e-mail: tohya.yukinobu@nihon-u.ac.jp

(C)2012 The Japanese Society of Veterinary Science
}

or intestinal material were separated by centrifugation at 15,000 rpm for $5 \mathrm{~min}$, and then viral RNA was extracted from the supernatants using a QIAamp Viral RNA Mini Kit (QIAGEN, Valencia, CA, U.S.A.) and Yeast RNA (Applied Biosystems, Foster City, CA, U.S.A.) as a carrier according to the manufacturer's instructions. We used the MNVspecific primer sets [7], MNV-F1 (external sense, 5'-GCCATGCATGGTGAAAAG-3', 4887-4904), MNV-R1 (external antisense, 5'-CATGCARACCAGGCGCATAG-3', 5588-5607), MNV-F2 (internal sense, 5'-ACARTGGATGCTGAGACC-3', 5010-5027), and MNV-R2 (internal antisense, 5'-CAACCACCTTGCCAGCAG-3', 5408-5425). The nucleotide positions described in this report correspond to those of the complete genome of the MNV-1 strain (AY228235). Viral RNA ( $5 \mu l$ ) was amplified by RT-PCR using One Step RT-PCR Kit Ver.2 -Dye Plus- (Takara Bio, Shiga, Japan) in a $50-\mu l$ volume containing $5 \mu l$ of $10 \mu \mathrm{M}$ outer primer set, $25 \mu l$ of $2 \times 1$-step Buffer and $2 \mu l$ of 1-step Enzyme Mix. The reaction conditions were: $50^{\circ} \mathrm{C}$ for 30 min, $94^{\circ} \mathrm{C}$ for $2 \mathrm{~min}, 40$ cycles at $94^{\circ} \mathrm{C}$ for $30 \mathrm{sec}, 50^{\circ} \mathrm{C}$ for $30 \mathrm{sec}$ and $72^{\circ} \mathrm{C}$ for $1 \mathrm{~min}$, followed by $72^{\circ} \mathrm{C}$ for $10 \mathrm{~min}$. Nested and semi-nested PCR included Takara Ex Taq (Takara Bio) and $2 \mu l$ of the RT-PCR product, and proceeded under the same conditions as described for RT-PCR. The PCR products were electrophoretically resolved in agarose gels and visualized using SYBR safe DNA gel stain (Invitrogen, Carlsbad, CA, U.S.A.) and UV illumination. The products of MNV-positive samples amplified by nested and semi-nested PCR were again electrophoretically resolved as described above, visualized using a Safe Imager 2.0 Blue Light Transilluminator (Invitrogen) and purified using a QIAquick Gel Extraction Kit (QIAGEN). Both strands of the purified PCR product were sequenced using the BigDye Cycle Sequencing Kit (Applied Biosystems) and a 


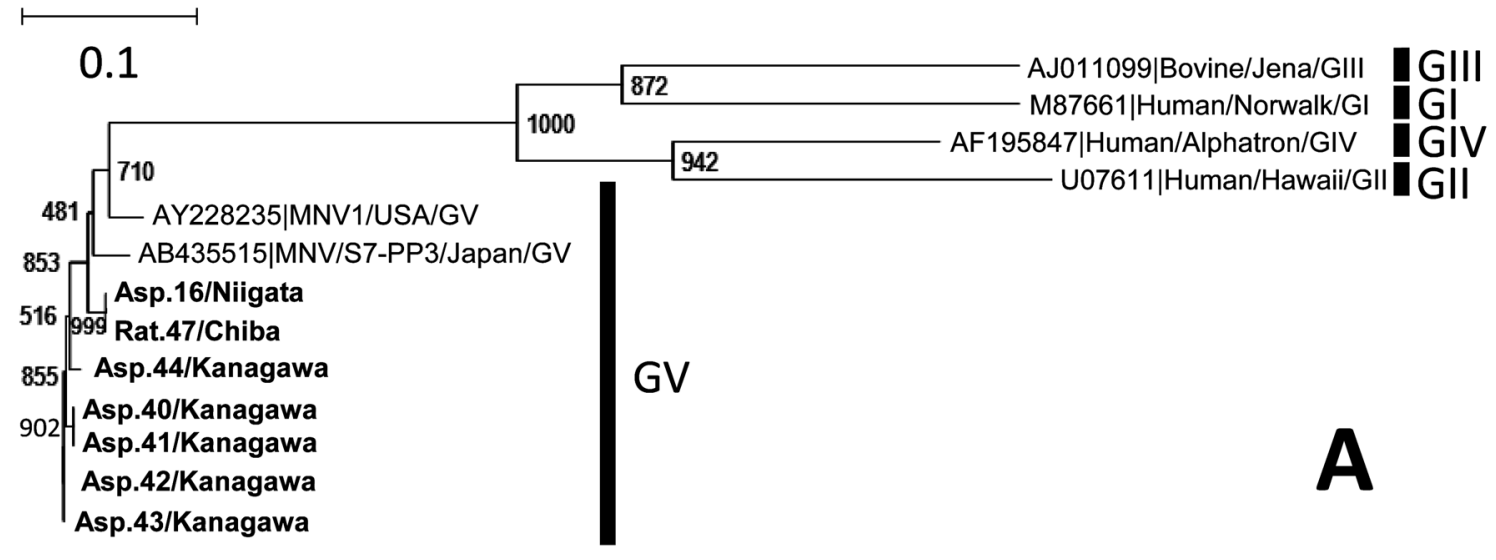

\section{1}

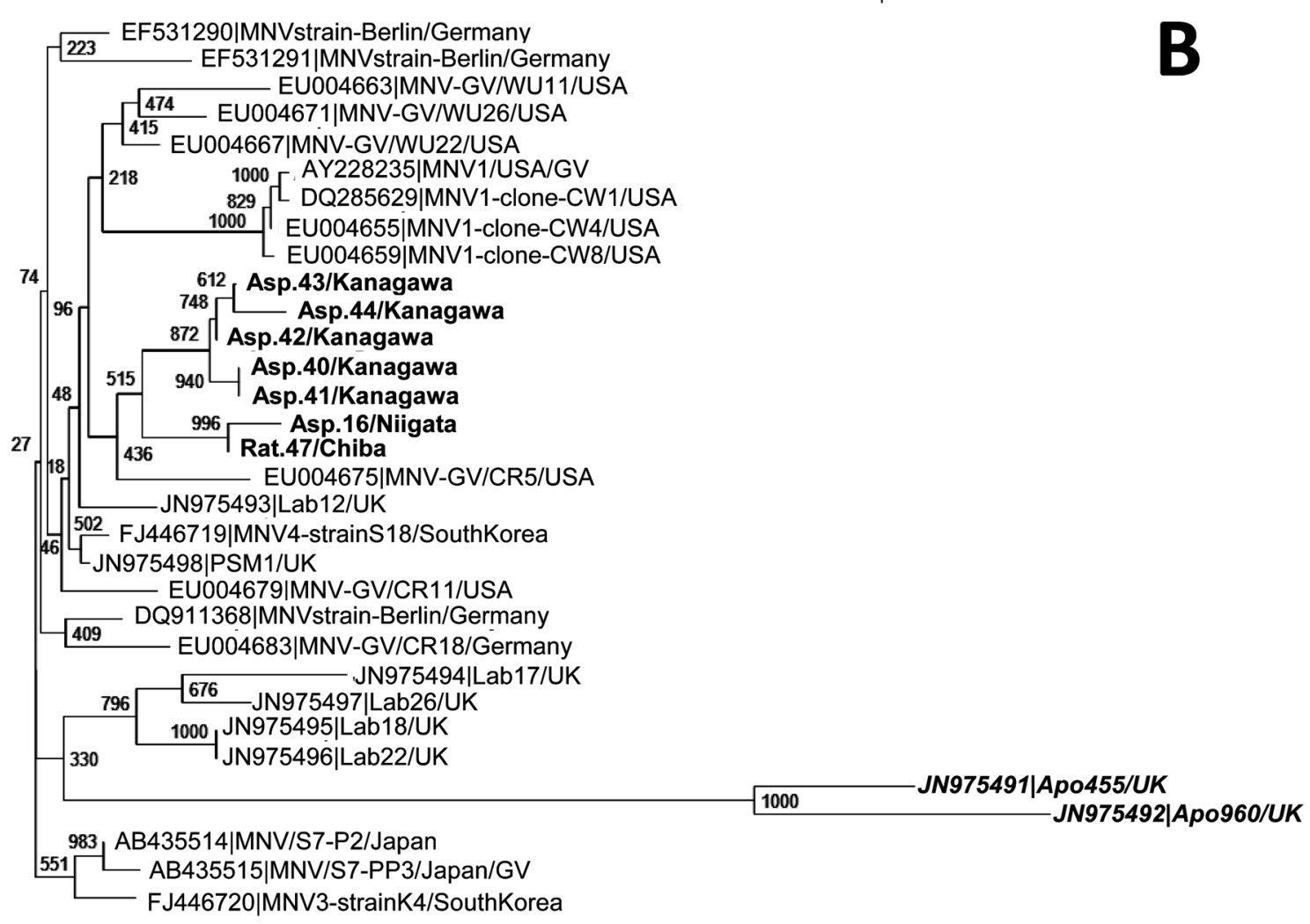

Fig. 1. Phylogenetic trees based on sequences of the open reading frame 1 (ORF1)-ORF2 junction region of (A) murine norovirus (MNV)-like genes detected herein (351 nucleotides; 4965-5466) and of norovirus genes of genogroup I (GI)-GV obtained from DDBJ (http://www.ddbj.nig.ac.jp/) and (B) MNV-like genes detected in this study (502 nucleotides; 4965-5466) and MNV genes obtained from DDBJ. The nucleotide positions correspond to those of the complete genome of the MNV-1 strain (AY228235). MNV detected in this study are described as bold and those of $A$. sylvatics-derived MNV strains are as bold and Italic. Names and GenBank accession numbers of samples detected in this study are as follows: Asp.16/Niigata (AB684730), Asp.40/ Kanagawa (AB684731), Asp.41/Kanagawa (AB684732), Asp.42/Kanagawa (AB684733), Asp.43/Kanagawa (AB684734), Asp.44/Kanagawa (AB684735), and Rat.47/Chiba (AB684736). Phylogenetic trees were generated using MEGA4.1 (http:// www. megasoftware.net/). Bootstrap values (1000 replicates) are indicated at branch nodes. Branch lengths are proportional to genetic distance. Scale bar indicates nucleotide substitutions per site. 
3130 Genetic Analyzer (Applied Biosystems). Nucleotide sequences were aligned with BioEdit (http://www.mbio. ncsu.edu/bioedit/bioedit.html) with reference MNV strains. Phylogenetic trees based on sequences of the open reading frame (ORF) 1-ORF2 junction region (351 nucleotides; 5056-5406 and 502 nucleotides; 4965-5466) were generated using MEGA4.1 (http://www.megasoftware.net/).

None of the samples were MNV-positive after the first RTPCR, but 7 (14.9\%) of 47 samples were positive after nested and semi-nested PCR. Six were isolated from Apodemus speciosus and one from Rattus rattus. Genetic analyses of the PCR products showed that the sequences detected herein had substantial homology with the GV MNV derived from laboratory mice (Fig. 1A), but formed a cluster distinct from those of known MNV (Fig. 1B). Interestingly, the cluster of MNV in wild rodents (A. specious and R. rattus) in Japan was separated from clusters of MNV not only from mice but also from wild rodents (A. sylvaticus) in UK. Furthermore, the sequences obtained from isolates of Niigata ( $A$. speciosus) and Chiba ( $R$. rattus) formed a cluster distinct from that formed by Kanagawa (A. speciosus) isolates (Fig. 1B). These results suggest that the prevalence of MNV in wild rodents and the genetic diversity of MNV depend on their host species or distribution.

In these phylogenetic analyses, unfortunately, we could not obtain strong bootstrap support at half of the nodes (Fig. 1B), probably owing to high sequence similarity in the genomic region used for the analyses. Most of the genomic regions (351 nucleotides; 5056-5406 for Fig. 1A and 502 nucleotides; 4965-5466 for Fig. 1B) include the 5' region of ORF4 (5069-5707) which is an alternative reading frame overlapping ORF2 and highly conserved in MNV strains [9, 13]. Therefore, to further characterize the MNV detected in the wild rodents, we attempted to sequence the VP1 and VP2 coding regions in MNV-positive samples. Additional primers were designed to amplify the VP1 and VP2 coding regions from known sequences of MNV obtained from DDBJ and the new sequences determined in this study for RT-PCR and nested-PCR. However, a PCR product was not generated (data not shown), indicating a very low concentration and/or sequence diversity of viral RNA among the samples.

We also attempted to isolate viruses using cell culture. Fecal or intestinal suspensions $(2.5 \%$ or $5 \%$ ) of 5 (4 from $A$. speciosua and 1 from $R$. rattus) of $7 \mathrm{MNV}$-positive samples were separated by centrifugation at $15,000 \mathrm{rpm}$ for $5 \mathrm{~min}$, and then RAW 264.7 cells were inoculated with filtered supernatants. The cells were observed for 5 days, frozen at $-80^{\circ} \mathrm{C}$ and then blindly passaged up to 10 times using the supernatants of frozen-thawed cells as inocula. After each blind passage, RNA was extracted from the supernatants of frozen-thawed cells, and then RT-PCR and nested PCR proceeded as described above to evaluate viral growth. We found neither a cytopathic effect of MNV nor an increase in viral RNA according to PCR assays (data not shown). These results are coincident with an unsuccessful result in a previous study which also attempted to grow the A. sylvaticsderived MNV in RAW264.7 macrophages under conditions where $M$. musculus-derived MNV was successfully cultured
[12]. Although it could be only attributed to low viral concentration in the samples, the possibility that MNV infecting A. speciosus or $R$. rattus has tropism that differs from that of MNV infecting $M$. musculus could not be ruled out.

In conclusion, we detected novel MNV-like sequences in $14.9 \%(7 / 47)$ of samples derived from wild rodents in Japan. Considering that the MNV sequences detected in this study formed a cluster distinct from that of known MNV within $\mathrm{GV}$ and that nucleotide sequence differences were observed even among wild rodents, MNV might have genetic diversity dependent on their host species or distribution. This is the first report suggesting the prevalence of $\mathrm{MNV}$ in $A$. speciosus and $R$. rattus.

ACKNOWLEDGMENTS. We thank Dr. Sadao Nogami for providing samples and Drs. Takuya Yamaguchi and Shingo Sato for excellent technical support. This study was partially supported by the Strategic Research Base Development Program entitled, "International research on epidemiology of zoonoses and training for young researchers" from the Ministry of Education, Culture, Sports, Science and Technology, Japan.

\section{REFERENCES}

1. Cox, C., Cao, S. and Lu, Y. 2009. Enhanced detection and study of murine norovirus-1 using a more efficient microglial cell line. Virol. J. 6: 196. [Medline] [CrossRef]

2. Duizer, E., Schwab, K. J., Neill, F. H., Atmar, R. L., Koopmans, M. P. and Estes, M. K. 2004. Laboratory efforts to cultivate noroviruses. J. Gen. Virol. 85: 79-87. [Medline] [CrossRef]

3. Glass, R. I., Parashar, U. D. and Estes, M. K. 2009. Norovirus gastroenteritis. N. Engl. J. Med. 361: 1776-1785. [Medline] [CrossRef]

4. Green, K. Y. 2006. Caliciviridae: The Noroviruses. pp. 949-979. In: Fields Virology 5th ed., vol. I (Knipe, D. M. and Howley, P. M, eds.), Lippincott Williams \& Wilkins, Philadelphia.

5. Henderson, K. S. 2008. Murine norovirus, a recently discovered and highly prevalent viral agent of mice. Lab. Anim. (NY) 37: 314-320. [Medline] [CrossRef]

6. Karst, S. M., Wobus, C. E., Lay, M., Davidson, J. and Virgin, H. W. 4th. 2003. STAT1-dependent innate immunity to a Norwalklike virus. Science 299: 1575-1578. [Medline] [CrossRef]

7. Kitajima, M., Oka, T., Tohya, Y., Katayama, H., Takeda, N. and Katayama, K. 2009. Development of a broadly reactive nested reverse transcription-PCR assay to detect murine noroviruses, and investigation of the prevalence of murine noroviruses in laboratory mice in Japan. Microbiol. Immunol. 53: 531-534. [Medline] [CrossRef]

8. Lay, M. K., Atmar, R. L., Guix, S., Bharadwaj, U., He, H., Neill, F. H., Sastry, K., J., Yao, Q. and Estes, M. K. 2010. Norwalk virus does not replicate in human macrophages or dendritic cells derived from the peripheral blood of susceptible humans. Virology 406: 1-11. [Medline] [CrossRef]

9. McFadden, N., Bailey, D., Carrara, G., Benson, A., Chaudhry, Y., Shortland, A., Heeney, J., Yarovinsky, F., Simmonds, P., Macdonald, A. and Goodfellow, I. 2011. Norovirus regulation of the innate immune response and apoptosis occurs via the product of the alternative open reading frame 4. PLoS Pathog. 7: e1002413. [Medline] [CrossRef]

10. Patel, M. M., Hall, A. J., Vinjé, J. and Parashar, U. D. 2009. 
Noroviruses: a comprehensive review. J. Clin. Virol. 44: 1-8. [Medline] [CrossRef]

11. Siebenga, J. J., Duizer, E. and Koopmans, M. Norovirus Epidemiology. 2010. pp. 1-24. In: Caliciviruses Molecular and Cellular Virology (Hansman, G. S., Jiang, X. and Green, K. Y. eds.), Caister Academic Press, Norfolk.

12. Smith, D. B., McFadden, N., Blundell, R. J., Meredith, A. and Simmonds, P. 2012. Diversity of murine norovirus in wild-rodent populations: species-specific associations suggest an ancient divergence. J. Gen. Virol. 93: 259-266. [Medline] [CrossRef]

13. Thackray, L. B., Wobus, C. E., Chachu, K. A., Liu, B., Alegre, E. R., Henderson, K. S., Kelley, S. T. and Virgin, H. W. 4th. 2007. Murine noroviruses comprising a single genogroup exhibit biological diversity despite limited sequence divergence. J. Virol.
81: 10460-10473. [Medline] [CrossRef]

14. Wobus, C. E., Karst, S. M., Thackray, L. B., Chang, K. O., Sosnovtsev, S. V., Belliot, G., Krug, A., Mackenzie, J. M., Green, K. Y. and Virgin, H. W. 4th. 2004. Replication of Norovirus in cell culture reveals a tropism for dendritic cells and macrophages. PLoS Biol. 2: e432. [Medline] [CrossRef]

15. Wobus, C. E., Thackray, L. B. and Virgin, H. W. 4th. 2006. Murine norovirus: a model system to study norovirus biology and pathogenesis. J. Virol. 80: 5104-5112. [Medline] [CrossRef]

16. Zheng, D. P., Ando, T., Fankhauser, R. L., Beard, R. S., Glass, R. I. and Monroe, S. S. 2006. Norovirus classification and proposed strain nomenclature. Virology 346: 312-323. [Medline] [CrossRef] 